\title{
INTERTEXTUALIDADE: O FENÔMENO DO DÉTOURNEMENT EM ANÚNCIOS PUBLICITÁRIOS DE PRODUTOS COMERCIAIS
}

\author{
Francisco Edivan da Silva ${ }^{1}$ \\ Antônio Luciano Pontes ${ }^{2}$
}

RESUMO: No presente estudo, procuramos pesquisar e analisar a ocorrência de détournements em slogans de anúncios publicitários e propagandas comerciais, com base nos estudos propostos por Grésillon \& Maingueneau (1984) e aprofundados por Koch, Bentes e Cavalcante (2008). A partir dessa proposta, desdobraram-se os seguintes objetivos: investigar tipos de texto que geram détournement, analisar as operações presentes na passagem do texto-fonte para o texto intertextual e descrever as categorias linguísticas que representam a operação do détournement. Ao final, sintetizamos os resultados obtidos, dando ênfase àqueles de maior relevância, e, com isso, mostramos como nossas questões de pesquisa foram respondidas e, consequentemente, foram atingidos nossos objetivos.

Palavras-chave: Intertextualidade. Détournement. Polifonia.

ABSTRACT: In the present study, we seek to research and analyze the occurrence of détournements in advertising slogans and commercial advertisements, based on the studies proposed by Grésillon \& Maingueneau (1984) and further developed by Koch, Bentes and Cavalcante (2008). From this proposal, the following objectives were developed: to investigate types of text that generate détournement, to analyze the operations present in the passage from the source text to the intertextual text and to describe the linguistic categories that represent the détournement operations. In the end, we summarize the results obtained, giving emphasis to those of greater relevance, and, with that, we show how our research questions were answered and, consequently, our objectives were achieved.

Keywords: Intertextuality. Détournement. Polyphony.

\footnotetext{
'Atualmente está fazendo Especialização em Docência do Ensino Básico e Superior pela Faculdade Estratego de Belém do Pará. Desenvolve estudos envolvendo a intertextualidade, em especial, voltados para a Literatura. E- mail: fedivan2or4@gmail.com

${ }^{2}$ Doutorado em Lingüística (UNESP), sob a orientação da Professora Doutora Ieda Maria Alves (USP). Mestre em Língua Portuguesa (UFPB). Membro do grupo de pesquisa cadastrado no CNPq Lexicografia, Terminologia e Ensino (LETENS). Professor Titular no curso de Letras da UERN, onde está ligado ao Programa de Pós-graduação em Letras (PPGL) e Mestrado Profissionalizante de Letras (PROFLETRAS). Está vinculado ao Programa de Pós-graduação de Linguística Aplicada (PosLA) da Universidade Estadual do Ceará. Participa como membro-efetivo do GT Lexicologia, Lexicografia e Terminologia, da ANPOLL. Desenvolve pesquisa nas áreas de Geolinguística, Lexicografia teórica, fazendo interface com a Teoria da Multimodalidade, Análise do Discurso, Geografia Linguística. Autor de diversos livros, capítulos e artigos sobre Metalexicografia Pedagógica, Lexicografia Multimodal, Lexicografia prática. Atualmente integra a equipe do Atlas Linguístico do Brasil e do Projeto Tesouro do Léxico Patrimonial Galego e Português. O pesquisador é vice-líder do Grupo de Pesquisa em Estudos Funcionalistas (GPEF/UERN) e líder do Grupo de Pesquisa Lexicografia, Terminologia e Ensino (LETENS/UECE), cadastrado no CNPq.
} 


\section{INTRODUÇÃO}

O nosso olhar será lançado sob o viés da intertextualidade, um grande tema que tem sido estudado sob perspectivas teóricas distintas, como na Linguística Textual, na Teoria Literária, entre outras. Porém, poucos trabalhos acadêmicos são alicerçados sob o fenômeno do détournement, um termo criado por Grésillon \& Maingueneau (1984), para designar a alteração, tanto na forma como no conteúdo de provérbios, slogans ou frases feitas, que podem ser do tipo lúdico ou militante, este último com o objetivo de captação ou de subversão, sendo que a subversão ocorre com maior frequência. O détournement é muito usado em publicidades, assim como também em outras formas de linguagem, como, por exemplo, em músicas, humor, sabedoria popular etc., ora opondo-se ao locutor, ora aderindo ao seu pensamento. Portanto, nossa pesquisa está voltada para a intertextualidade, mais especificamente para o fenômeno do détournement em anúncios publicitários de produtos comerciais.

A origem do conceito de intertextualidade deu-se na década de 196o, por Julia Kristeva, uma crítica literária e filósofa francesa, para explicar o dialogismo de Mikhail Bakhtin da década de 1920. Para Bakhtin (1999), o texto não subsiste sem outro texto, quer atraindo-o ou rejeitando-o, permitindo que ocorra um diálogo entre duas ou mais vozes, entre dois ou mais discursos.

Como afirmam Koch, Bentes e Cavalcante (2008), usando as palavras de Bakhtin,

O texto só ganha vida em contato com outro texto (com contexto). Somente neste ponto de contato entre textos é que uma luz brilha, iluminando tanto o posterior como o anterior, juntando dado texto a um diálogo. Enfatizamos que esse contato é um contato dialógico entre textos... Por trás desse contato está um contato de personalidades e não de coisas (KOCH, BENTES, CAVALCANTE, 2008, p. 16).

Para Koch, a intertextualidade pode ser de uma existência ampla, em sentido latu sensu, que diz respeito ao fato de que nenhum discurso é absolutamente original, que os discursos nascem a partir de outros já existentes; ou pode acontecer quando um texto está inserido em outro texto (intertexto) produzido anteriormente e que faz parte da memória social de uma coletividade ou da memória discursiva dos interlocutores, que é o sentido sticto sensu (nos aprofundaremos mais adiante sobre cada um dos dois sentidos). 
Kristeva (1967) afirma que, todo texto é um intertexto, pois qualquer texto se constrói como um mosaico de outros textos que são absorvidos e transformados em outros textos. Isso significa dizer que um texto permuta diversos textos ou fragmentos de textos que existem ao seu redor e dentro dele mesmo (latu sensu). O que implica dizer que outros textos estão presentes nele, isto é, outros textos o compõem, em níveis variáveis, com características mais ou menos evidentes. O texto é um objeto heterogêneo, que pode originar de outro texto, predeterminar outros textos, conversar com outros, aludir ou se opor a outros etc.

Maingueneau (1997) distingue o intertexto da intertextualidade. Para ele o intertexto pode ser entendido como "o conjunto de fragmentos que uma formação discursiva cita" e por intertextualidade "o tipo de citação que a formação discursiva define como legítima através de sua própria prática".

A intertextualidade tem sido relacionada de diversos tipos, cada tipo comportando suas próprias características. Pode ser intertextualidade de face stricto sensu, intertextualidade de face latu sensu e, ainda, a polifonia. As duas primeiras já descritas brevemente acima, e esta última, introduzida por Bakhtin ao realizar trabalhos sobre literatura, a respeito dos romances de Dostoievski, em que relata haver várias "vozes" que se exprimem sem que nenhuma seja dominante. Além do autor e do interlocutor presumido, há outras "vozes” num enunciado. Essas vozes podem aparecer de maneira evidente, ou seja, de forma explícita, marcada linguisticamente pelo discurso direto ou apenas pela relação entre as vozes. A polifonia, portanto, se caracteriza, não somente como multiplicidade de vozes ou de vários pontos de vistas sobre o mundo, mas um dialogismo levado ao extremo na esfera literária.

A intertextualidade pode ser dos tipos: implícita, explícita, estilística, temática, tipológica, intergenérica, e ainda, détournement. Nos capítulos posteriores definiremos brevemente cada uma delas, dando atenção especial ao détournement.

O corpus é composto pela análise de 2 (dois) anúncios publicitário e propagandas comerciais de épocas distintas, em que aparecem slogans com algum tipo de intertextualidade para verificação se houve détournement, quais tipos de détournement aconteceram, que operações estão presentes na passagem do texto-fonte para o intertextual e descrever as categorias linguísticas responsáveis por essas operações. A escolha desse 
produto se deu por ele ser muito conhecido e por ter propagandas que ficam na lembrança das pessoas por bastante tempo. Selecionamos, portanto, doze propagandas e anúncios comerciais de épocas variadas, retiradas de meios de difusão diversos. O motivo da escolha dessas imagens se deu devido contemplar alguns assuntos que a base teórica não contemplou ou pela presença de novas operações de détournement observadas nas imagens escolhidas.

A coleta dos materiais foi feita através dos portais eletrônicos da empresa mencionada, por outros sites da internet, propagandas televisivas, folders, anúncios, etc.

\section{FUNDAMENTAÇÃO TEÓRICA}

Em um primeiro momento apresentaremos a intertextualidade em algumas abordagens teóricas, dando ênfase a sua origem, a partir do conceito de Kristeva, que por sua vez, baseia-se em Bakhtin. Destacaremos os estudos apresentados por Koch, Bentes e Cavalcante a respeito da intertextualidade stricto sensu e latu sensu, faremos uma distinção entre intertextualidade e polifonia e, por fim, definiremos o détournement e seus tipos.

\subsection{Intertextualidade: abordagens teóricas}

A origem do conceito de intertextualidade deu-se na década de 1960, por Julia Kristeva, uma crítica literária e filósofa francesa, para explicar o dialogismo de Mikhail Bakhtin da década de 1920 , esse termo, no entanto não foi criado por Bakhtin, não aparecendo, portanto, na obra do autor. Esse vocábulo foi introduzido por Kristeva em sua apresentação de Bakhtin na França, em uma publicação feita em 1967, na revista Critique. Kristeva chama de texto o que Bakhtin chama de enunciado, e acaba por designar por intertextualidade a noção de dialogismo. Alguns autores, porém, discordam do emprego do termo intertextualidade para substituir o termo dialogismo. Bem como entre a distinção entre texto e enunciado.

Para Bakhtin (1999), o texto não subsiste sem outro texto, quer atraindo-o ou rejeitando-o, permitindo que ocorra um diálogo entre duas ou mais vozes, entre dois ou mais discursos.

Como afirma Koch, Bentes e Cavalcante, usando as palavras de Bakhtin, 


\begin{abstract}
O texto só ganha vida em contato com outro texto (com contexto). Somente neste ponto de contato entre textos é que uma luz brilha, iluminando tanto o posterior como o anterior, juntando dado texto a um diálogo. Enfatizamos que esse contato é um contato dialógico entre textos... Por trás desse contato está um contato de personalidades e não de coisas (KOCH, BENTES; CAVALCANTE, 2008, p. 16).
\end{abstract}

Para Koch, a intertextualidade pode ser de uma existência ampla, em sentido latu sensu, que diz respeito ao fato de que nenhum discurso é absolutamente original, que os discursos nascem a partir de outros já existentes; ou pode acontecer quando um texto está inserido em outro texto (intertexto) produzido anteriormente e que faz parte da memória social de uma coletividade ou da memória discursiva dos interlocutores, que é o sentido sticto sensu.

Kristeva afirma que, todo texto é um intertexto, pois qualquer texto se constrói como um mosaico de outros textos que são absorvidos e transformados em outros textos. Isso significa dizer que um texto permuta diversos textos ou fragmentos de textos que existem ao seu redor e dentro dele mesmo (latu sensu). O que implica dizer que outros textos estão presentes nele, isto é, outros textos o compões, em níveis variáveis, com características mais ou menos evidentes. O texto é um objeto heterogêneo, que pode

originar de outro texto, predeterminar outros textos, conversar com outros, aludir ou se opor a outros etc.

Maingueneau (1997) distingue o intertexto da intertextualidade. Para ele o intertexto pode ser entendido como "o conjunto de fragmentos que uma formação discursiva cita" e por intertextualidade "o tipo de citação que a formação discursiva define como legítima através de sua própria prática”.

\title{
2.1.I Intertextualidade latu sensu
}

A intertextualidade de face latu sensu é um conceito próximo ao conceito de interdiscursividade, afirmando, portanto que nenhum discurso é absolutamente original, isto é, os discursos nascem a partir de outros discursos já existentes. Como Maingueneau (1976 apud $\mathrm{KOCH}, 2008$, p. I44) “um discurso [...] constrói-se através de um já dito em relação ao qual se toma posição".

Koch, Bentes e Cavalcante (2008), tecendo a amplitude das relações intertextuais, cunham o termo "transtextualidade", que é a transcendência textual do texto. A 
transtextualidade é a intertextualidade restrita de Genette, e pode ser considerada mais includente do que o termo já usual. Genette propôs essa expressão, a qual, segundo ele, diz mais respeito aos níveis de relações internas de um texto consigo próprio e com outros textos. Ou seja, na transtextualidade está incluso tudo o que coloca o texto, implícita ou explicitamente, em relação a outros textos. Dentre o emaranhado de relações possíveis, define cinco categorias dispostas em ordem crescente: a intertextualidade, a paratextualidade, a metatextualidade, a hipertextualidade e a arquitextualidade.

\section{I.2 Intertextualidade stricto sensu}

Em Koch, Bentes e Cavalcante (2008), a intertextualidade tem sido relacionada de diversos tipos, cada tipo comportando suas próprias características. Pode ser intertextualidade de face stricto sensu, ou seja, em sentido restrito acontece quando um texto está inserido em outro texto anteriormente produzido que faz parte da memória social de uma coletividade, isto é, intertexto. Essa memória social refere-se aos conhecimentos de mundo armazenados na mente dos sujeitos em forma de modelos cognitivos globais, permitindo, portanto, que um leitor possa enquadrá-lo em um determinado esquema que faça parte das produções de uma mesma cultura e estabelecer um diálogo com os outros.

Ainda na intertextualidade em sentido restrito o texto remete a outros textos ou a fragmentos de outros textos, estabelecendo, com os mesmos, uma relação. Pode, portanto, a intertextualidade de sentido restrito, comportar características próprias, alcançando diversas maneiras de se relacionar com outros textos, tais como: intertextualidade intergenérica, que ocorre quando as práticas sociais ou cenas comunicativas de que participam certos sujeitos determinam a existência dos chamados gêneros do discurso, com a forma composicional, conteúdo temático, estilo, circunstâncias de uso e propósito de comunicação próprio. Pode ocorrer, também, que se apresentem gêneros pertencentes a outras molduras comunicativas no lugar das práticas sociais, com o objetivo, evidentemente, de produzir determinados efeitos de sentido; intertextualidade tipológica, que decorre do fato de se poder depreender, entre determinadas sequências ou tipos textuais, um conjunto de características comuns, quanto em estruturação, seleção lexical, 
uso de tempos verbais, advérbios e outros elementos dêiticos, que permitem reconhecê-las por pertencer a determinadas classes.

Van Dijk (1983) denomina essas características citadas acima como superestruturas, destacando como as mais estudadas a narrativa, a descritiva, a expositiva, a preditiva, a explicativa e a argumentativa; intertextualidade temática, pode ser encontrada em textos pertencentes a uma mesma área do saber ou pela mesma corrente de pensamento, além de textos literários, lendas que fazem parte do folclore, histórias em quadrinhos, canções de um mesmo compositor, livros, filmes etc.; intertextualidade estilística, ocorre quando o autor imita, repete, parodia certos estilos ou variedades linguísticas com propósitos distintos, é muito comum na linguagem bíblica, em determinados gêneros, autores ou seguimentos da sociedade; intertextualidade explícita, é a que ocorre quando um outro texto ou fragmento é citado, e é atribuído outro enunciador explicitamente, esse tipo de intertextualidade ocorre, principalmente em resenhas, resumo, e citações; intertextualidade implícita, é quando há uma apropriação de um texto de outro enunciador sem que seja feita menção explícita da fonte, com objetivos de argumentar, contradizer, questionar etc., nesse caso pressupõe-se que o leitor já tenha um conhecimento prévio do texto original.

A intertextualidade em sentido restrito em Koch, Bentes e Cavalcante (2008), foi repensada, ganhando uma nova categorização, em intertextualidade temática, estilística, explícita e implícita, além da compreensão de que o détournement englobaria a maioria dos

casos desse tipo de intertextualidade. Também foram postulados dois outros tipos de intertextualidade: a intergenérica e a tipológica. Começando por estas últimas, descreveremos a compreensão que as autoras postulam para cada tipo de intertextualidade stricto sensu, isto é, sentido restrito.

Portanto, para que se verifique que a intertextualidade intergenérica está presente em certos textos a mobilização do contexto sociocognitivo é essencial, pois é através dele que o leitor irá detectar a presença da ironia, do humor etc., que o leitor irá perceber e construir o sentido em consentimento com a proposta do texto.

\subsection{Détournement}

O détournement é um conceito criado por Grésillon e Maingueneau (1984), que fala sobre a possibilidade artística, política e ideológica etc., de tomar algum objeto (texto) 
criado pelo capitalismo ou pelo sistema político heterogêneo, "distorcendo" assim, seu significado e uso original propositalmente, para produzir um efeito crítico ou não.

O termo détournement, que tem origem francesa, não tem, portanto, uma tradução na língua portuguesa que se encaixe perfeitamente em seus termos sem sofrer alterações. Poderia ser traduzido como “distorção”, “malversação” ou “deturpação”. No entanto, sofreria alterações, não mantendo o significado original. Porém, ao se referirem ao fenômeno do détournement, Koch, Bentes e Cavalcante (2008), dizem que:

a noção de détournement - termo que, na falta de uma tradução que nos pareça satisfatória, preferimos manter no original - tal como formulada por Grésillon e Maingueneau (1984), se ampliada, seria capaz de subsumir grande parte dos casos de intertextualidade implícita (KOCH; BENTES; CAVALCANTE, 2008, p. 45).

Segundo esses autores, o détournement consiste em produzir um enunciado que possui as marcas linguísticas de uma enunciação proverbial, mas que não pertencem ao estoque dos provérbios reconhecidos. Segundo Koch, Bentes e Cavalcante (2008), Grésillon e Maingueneau, preconizam a existência de um détournement de tipo lúdico e de tipo militante. O détournement de tipo lúdico, são:

simples jogos com a sonoridade das palavras, como aqueles que as crianças - não só elas - gostam de inventar, que não estejam a serviço de uma manobra política ou ideológica, a par do outro, de tipo militante, que visa a dar autoridade a um enunciado (captação) ou a destruir aquela do provérbio em nome de interesses das mais diversas ordens (subversão) (KOCH, BENTES E CAVALCANTE, 2008. p. 45).

Portanto, há a existência de déturnement de tipo lúdico e de tipo militante, este último podendo ser por captação ou por subversão. Apesar de ser reconhecido por détournement proverbial, não se resume apenas ao provérbios, mas a todos os textos de conhecimento público como nas frases feitas, nos títulos de filmes, nas propagandas de produtos, no humor, nas músicas populares, em charges políticas, textos literários, slogans, clichês, passagens bíblicas e outro muitos.

Escolhemos trabalhar com slogans e propagandas de produtos por causa da grande circulação midiática, por ser de grande interesse das grandes marcas os slogans chamativos e propagandas que "caiam na graça” do povo para se tornarem seus produtos mais conhecidos. Quem não lembra das propagandas do empresa Sadia em que a Velhinha pede ao atendente, por nome Juvenal, $300 \mathrm{~g}$ de presunto Sadia, o atendente de imediato oferece outro presunto. A Velhinha responde: “- Nem a pau, Juvenal”. Essa expressão bastante 
conhecida popularmente, que significa uma negativa a algo pedido ou mandado. Essa expressão tem o mesmo valor semântico de outros ditos populares como: "nem que a vaca tussa", "de jeito nenhum".

\subsubsection{Détournement lúdico ou militante}

O détournement de tipo lúdico, para Koch, Bentes e Cavalcante (2008) "são simples jogos com sonoridade das palavras", A construção/desconstrução dessas unidades lexicais cristalizadas permite explorar o ludismo, com o surgimento de formações híbridas inusitadas, mas que devem atender à coesão interna de seus elementos e à associação ao provérbio original. Bartolomeu Campos Queirós, escritor brasileiro, “desconstrói” provérbios em "Ler, escrever e fazer conta de cabeça" (1996), em que se destaca o aspecto lúdico do détournement, que interpretamos como a reflexão pura, ingênua, inexperiente de uma criança, personagem principal do livro, diante de um enunciado tão complexo, tão abstrato, se deixando levar apenas pela literariedade. Conheçamos alguns exemplos retirados do livro:

Contei ao avô e ele me pediu segredo: 'Quem fala muito dá bom-dia a cavalo' afirmou. Fiquei na maior vontade de encontrar um cavalo para cumprimentar." "Na terra de cego quem abre cinema é doido."

“Matar duas sopas com um mosquito só.” (QUEIRÓS, 1996, p.)

O détournement de tipo militante, como o próprio nome sugere, é aquele que milita em prol de uma causa, seja por captação (dando autoridade a um enunciado) ou subversão (destruindo a intensão original do enunciado). O primeiro - militante por captação, a mensagem original se mantém presente para que, a partir daí, o interlocutor apreenda o resultado obtido por efeito da alteração proverbial. Como ocorre em:

- "Quando um não quer, os dois não compram em outro lugar. Só nas casas Bahia”, (propaganda das Casas Bahia, em 2005).

Podemos perceber que a ideia de solidariedade, parceria, bom senso, compreensão se mantém, apesar da substituição do verbo brigar por comprar. Isso observa também ao se comparar o provérbio.

- "O castigo vem a cavalo" às suas retextualizações em "O castigo vem a jato" ou "O castigo vem em tempo real". (Estratégia recorrente em textos publicitários). 
Neste caso a ideia de velocidade, rapidez se atualiza nas expressões "a jato" e "em tempo real" de acordo com a necessidade enunciativa de seu produtor.

Koch, Bentes e Cavalcante (2008) discordam, em parte, de Grésillon e Maingueneau, no que diz respeito ao détournement militante, afirmando que todo détournement é militante, em maior ou menor grau, visto que ele sempre vai orientar a construção de novos sentidos pelo interlocutor.

Ainda de acordo Koch, Bentes e Cavalcante (2008), "a extensão desse conceito às diversas formas de intertextualidade nas quais ocorre algum tipo de alteração - ou adulteração - de um texto-fonte [...] visando à produção de sentidos”. Para explicar essa teoria, as autoras recorrem para os rudimentos apresentados na Teoria da Enunciação de Oswald Ducrot (1980, 1984). Esta teoria postula a existência de dois ou mais enunciadores no interior de cada discurso, Er e E2, que representam, encenam perspectivas, ângulos, pontos de vista diferentes a um dos quais o locutor adere. Nesse caso, veremos a seguir como a teoria se aplica aos casos de retextualização de provérbios, frases feitas, ditos e canções populares, poemas, quando Er representa o enunciado original e E2 o enunciador que contradiz o texto-fonte, e ao qual o locutor adere ao proceder à retextualização.

Destacamos, portanto, que a extensão do conceito de détournemet às diversas formas de intertextualidade, nas quais ocorre algum tipo de alteração - ou adulteração - de um texto-fonte (que, no entanto, é importante que seja reconhecido, salvo nos casos de plágio), visa a reprodução de sentidos. Essas alterações são as operações de retextualização (Mascuschi, 200o; Travaglia, 2003), que tomam por base a Teoria da Enunciação (ou Teoria Polifônica) de Ducrot.

A seguir definiremos o détournemet de tipo militante por captação e por subversão.

\subsubsection{Détournement militante por captação ou por subversão}

O détournement de tipo militante, que pode ocorrer por captação ou subversão. Por captação, quando o enunciador mantém, no enunciado proverbial modificado, a mesma ideia contida no emprego do provérbio original, ou seja, visa dar autoridade ao enunciado dando evidência a uma estratégia de mudança na apropriação do provérbio; entretanto, mesmo com a alteração aplicada, o détournement proverbial mantém-se dentro de sua estrutura semântica original. Por exemplo: 
Eı: Quem vê cara, não vê AIDS. (Ministério da Saúde, Revista Veja, 1988).

E2: Quem vê cara, não vê coração. (Provérbio original).

Podemos verificar que o provérbio modificado por captação acompanha, nesse enunciado, o sentido da estrutura semântica utilizada, ou seja, o enunciador mantém, no enunciado proverbial modificado, a mesma ideia contida no emprego do provérbio original. Ocorre apenas uma substituição de vocábulo no final do enunciado. A mudança acontece somente na superfície linguística e não na base da interpretação proverbial.

$\mathrm{Na}$ segunda modificação proverbial, no entanto, como o próprio nome indica, o locutor procura subvertê-lo, discordando do teor semântico subjacente na composição do provérbio original, ou seja, visa destruir a ideia original em nome de interesses de diversas ordens. Por exemplo:

EI: O feitiço vai virar a favor da feiticeira. (Revista Veja, 1996).

E2: O feitiço vai virar contra a feiticeira. (Provérbio original).

Nesse enunciado, o provérbio modificado por subversão não acompanha o sentido da estrutura semântica utilizada, ou seja, o enunciador suscita uma contradição entre o sentido da condição genérica transmitida pela estrutura semântica original e o sentido da

enunciação resultante da distorção. Com a construção de enunciado de sentido subvertido, ocorre mudança na superfície linguística e na base da interpretação proverbial. Desse modo, a estratégia de subversão, segundo Maingueneau (1998, p.20), nesse tipo de modificação proverbial, "só imita para desqualificar a autoridade do texto fonte".

Distinguimos, portanto, o détournement de tipo militante por captação do détournement de tipo militante por subversão. Agora descreveremos algumas das categorias linguísticas que mais representam as operação de detournement.

\subsubsection{Détournement por Substituição}

Pode ocorrer através da substituição, como o próprio nome já indica, de fonemas ou de palavras.

- De fonemas

Ocorre quando apenas algum(uns) fonema(as) são substituídos, dando origem a novas palavras e novo sentido ao texto original.

Por exemplo: 
EI: "Prepare-se para levar um susto”. (Provérbio original).

E2: "Prepare-se para levar um surto". (Matéria veiculada pelo Jornal Folha de São Paulo com o tema: Não jogue lixo nas ruas).

Observemos que apenas um fonema foi substituído para dar origem a uma nova palavra e, por conseguinte, um novo sentido ao texto-fonte.

- De palavras

Ocorre quando apenas algum(umas) palavra(s) são substituídos, dando origem a novos sentidos ao texto original.

Por exemplo:

EI: "Quem espera sempre alcança". (Provérbio original).

E2: "Quem espera nunca alcança". (Chico Buarque, Bom Conselho).

Nesse exemplo pode-se observar que a palavra "sempre" fora substituída pela palavra "nunca", com sentido contrário. O sentido produzido é de contradição ao textofonte, dando origem a um novo sentido.

\subsubsection{Détournement por Acréscimo}

Pode ocorrer através de formulação adversativa, por inversão da polaridade afirmação/negação e por outros tipos de acréscimo.

- De formulação adversativa

Geralmente, após o texto-fonte, há um acréscimo de um outro texto que o contradiz, introduzido por uma conjunção adversativa.

Por exemplo:

EI: "Devagar se vai ao longe". (Provérbio original).

E2: "devagar se vai ao longe, mas leva muito tempo". (Texto modificado por acréscimo de formulação adversativa, em que a conjunção "mas” indica uma contradição ao que o texto original afirma).

- Por inversão da polaridade afirmação/negação

Nesse caso há uma inversão pelo acréscimo de uma negação ou de uma afirmação.

Vejamos o exemplo:

EI: “Devagar se vai ao longe”. (Provérbio original). 
E2: ““Devagar é que não se vai longe”. (Chico Buarque, Bom Conselho).

Percebe-se que há uma negação do texto-fonte pela expressão “que não". Observemos o segundo exemplo para melhor compreensão.

Er: "Quem vê cara, não vê coração". (Provérbio original).

E2: "O Instituto de Cardiologia não vê cara, só vê coração". (Propaganda do Instituto de Cardiologia do Rio Grande Do Sul, 1990).

Observe que há uma inversão dos polos de afirmação/negação, a primeira oração, que era afirmativa no texto original, passa a ser negativa, já a segunda sofre processo inverso.

- Outros tipos de acréscimo

EI: “A preguiça é a mãe de todos os males”. (Provérbio original).

E2: “A preguiça é a mãe de todos os males que não requerem muito esforço".

Nesse tipo de acréscimo não há uma contradição do provérbio original, mas uma afirmação.

\subsubsection{Détournemant por Supressão}

Ocorre quando há retirada de alguns termos ou de parte da palavra para causar o mesmo sentido ou não do sentido proposto pelo texto origem.

Por exemplo:

Eı: "Para bom entendedor, meia palavra basta". (Provérbio original).

E2: "Para bom entendedor, meia palavra bas". (L. F. Veríssimo, Mínimas).

Ou então:

Eı: "O que os olhos não veem, o coração não sente." (Provérbio original).

E2: "O que os olhos não veem, o coração sente".

No primeiro exemplo ocorreu a supressão de metade da palavra para concordar com o texto-base. Já no segundo exemplo há a supressão do termo "não", dando origem a um novo sentido, com o objetivo de discordar do texto original.

\subsubsection{Détournement por Transposição}

A transposição ocorre quando os termos principais são transpostos, ou seja, troca-se apenas de posição, como podemos observar no exemplo abaixo: 
EI: “Mais vale um pássaro na mão do que dois voando". (Provérbio original).

E2: "Mais vale um pássaro voando do que dois na mão". (Campanha ecológica veiculada pelo Zero Hora, em 1989).

Observemos que o termo "voando" e "mão" assumem uma nova posição, consequentemente, ganhando um sentido diferente.

Descrevemos acima as categorias linguísticas, ou seja, as operações presentes na passagem do texto fonte para o texto intertextual, que representam as operação de detournement. A seguir investigaremos o textos geradores de détournemet e onde são veiculados com maior frequência.

\subsubsection{Détournement em provérbios, freses feitas, clichês, slogans etc.}

Podemos verificar, a partir dos exemplos apresentados acima,

$$
\begin{aligned}
& \text { que o détournement envolve, em grande parte dos casos de subversão, uma } \\
& \text { contradição ao texto-fonte, por intermédio da negação de uma parte ou do todo, } \\
& \text { pelo apagamento da negação que aquele encerra, ou, ainda, pelo acréscimo de } \\
& \text { expressões adversativas. Por maio destas formas de retextualização, isto é, de } \\
& \text { transformação de um texto em outro [...] (KOCH, BENTES E } \\
& \text { CAVALCANTE, 2008, p. 5I). }
\end{aligned}
$$

Portanto, por meio das formas de retextualização (substituição, acréscimo, supressão e transposição) operam-se diversos tipos de détournement. Mencionaremos, a seguir, os tipos de textos que geram détournement.

Diversos tipos de texto podem gerar détournement, entre os mais comuns podemos mencionar:

- Détournement de provérbios populares, frases feitas, títulos de filmes, muito frequente, por exemplo, na publicidade, no humor, na música popular, em “charges" políticas etc.

Já apresentamos acima as operações que envolve os tipos de détournement, então, apresentaremos apenas os exemplos que se enquadram em cada texto gerador de détournement. Por exemplo: textos humorísticos (Provérbios do Planalto, de Jô Soares; Mímias, de Luís Fernando Veríssimo).

Vejamos os seguintes exemplos:

Er: "O paciente inglês" (filme americano, lançado em 1997 no Brasil). 
E2: "O impaciente francês" (slogan da propaganda de um carro da Renault, apresentada em outdoors na mesma época do filme).

EI: "No dia das mães, dê um presente X".

Er: "Mãe só tem uma". (Frases feitas, de conhecimento popular).

E2: "No dia das mães dê um presente Casa Pio. Sua mãe merece um presente Casa Pio" (comercial veiculado na tv em abril/maio de 2019).

E2: "No dia das mães, dê um anel Drenysun. Afinal, mãos só tem duas" (Anúncio da relojoaria Drenysun, publicada na revista Veja, por ocasião do dia das mães).

\section{- Détournement de textos ou títulos de textos literários.}

Aparece frequentemente, não só na publicidade e na propaganda, mas também em outros textos literários.

Vejamos os exemplos:

EI: "Vou-me embora pra Pasárgada

Lá sou amigo do rei...” (poema de Manuel Bandeira).

E2: "Fui-me embora de Pasárgada...

(Lá tem amigos do rei DEMAIS)” (Charge publicada no Jornal O Estado de São Paulo, em ro/o5/ı9).

Os exemplos são numerosos, podendo, não apenas, modificar o título, mas pode manter-se o título original e o conteúdo ser modificado. Cabe, porém, questionar se, quando se tem um novo texto, com o mesmo título, trata-se da intertextualidade implícita (por não fazer menção ao autor), ou intertextualidade explícita (já que o título é citado, em certos casos, tal qual o original. Nesse caso o título servirá como forma de acesso do intertexto, desde que esteja presente na memória discursiva do leitor).

- Détournement de provérbios, frases feitas, clichês, slogans, passagens bíblicas etc.

Pode acontecer em enunciados do tipo concessivo (operação de contrajunção) por meio de adjunções. Por exemplo:

Eı: "Os últimos serão os primeiros".

E2: “Os últimos serão os primeiros, mas só em caso de retirada”.

Er: "Devagar se vai ao longe". 
E2: "Devagar é que não se vai a lugar nenhum" (Retirado do meme Táticas de Guerra, acesso em 09/or/20).

"Devagar se vai ao longe, mas leva muito tempo" (Mínimas, Luís Fernando Veríssimo).

"Devagar é que não se vai longe" (Bom Conselho, Chico Buarque de Holanda).

- Détournement de fábulas tradicionais.

O Détournement de fábulas tradicionais acontece quando as mesmas são reescritas, tendo vários tipos de propósitos a serem alcançados, dentre eles: o humor, as críticas, divergir ou aderir à moral da história, e outros motivos, assim como podemos observar no exemplo a seguir:

Er: “A lebre e a tartaruga

Era uma vez... uma lebre e uma tartaruga. A lebre viva caçoando da lerdeza da tartaruga. Certa vez, a tartaruga já muito cansada por ser alvo de gozações, desafiou a lebre para uma corrida. A lebre muito segura de si, aceitou prontamente. Não perdendo tempo, a tartaruga pois-se a caminhar, com seus passinhos lentos, porém, firmes. Logo a lebre ultrapassou a adversária, e vendo que ganharia fácil, parou e resolveu cochilar. Quando acordou, não viu a tartaruga e começou a correr. Já na reta final, viu finalmente a sua adversária cruzando a linha de chegada, toda sorridente.

Moral: Devagar se vai ao longe!”

E2: “A lebre e a tartaruga

A lebre sempre dizia que era a melhor de todas e que conseguia ganhas até de um gueopardo, mas a tartaruga, cansada de ver ela contando vantagem, desafiou a lebre para uma corrida. A lebre quase caiu de tanto rir e falou:

- Você tá de brincadeira?

A raposa era a juíza e recebia as apostas. Quando começou a corrida, a lebre percebeu que a tartaruga já estava na linha de chegada. A lebre desesperada perguntou:

- Como?! Você me passou?!

E a tartaruga falou:

- Claro. Eu sou um gueopardo fantasiado de tartaruga.

Moral: Não fale do que você não tem certeza" (Rafael Oliveira, Rafael Marçal e Enrique Fernandes). 
Nesse caso, o autor da fábula que sofreu o détournement, não apenas recriou a moral da história, mas trocou, também, as personagens, ao invés de ser uma tartaruga, era um "gueopardo" fantasiado de tartaruga. De fato, como podemos perceber, os textos que sofrem détournements têm sempre valor argumentativo que difere do texto-fonte, seja em maior ou menor grau. Embora o autor seja adepto, ou seja, haja captação do pensamento do texto-fonte, tem-se uma nova carga semântica presente no novo texto.

\section{- Détournement de hinos e canções populares.}

Ocorre quando hinos ou uma canções populares são parodiados, com o intuito de fazer humor, entre outras intenções. Vejamos os exemplos:

EI: “Atirei o pau no gato-to / Mas o gato-to não morreu-reu-reu / Dona Chicaca adimirou-se-se / Do berro, do berro que o gato deu / Miau” (Canção popular).

E2: “Atirei o pau no gato / Mas o gato não morreu! / Dona Chica admirou-se / Do berrou que o gato deu! / Hei! Chica! Deixe o gato em paz! / Não vamos traumatizar o coitado do animal / Só joguei o pau no bicho para ouvir o miau" (Falcão, compositor e humorista cearense).

\subsubsection{Détournement de entremeio}

A essa categorização encontramos mais um tipo de détournement, o détournement proverbial de entremeio, nele observamos a existência de um outro recurso argumentativo, no qual o enunciador, em um produtivo jogo de palavras, capta e, ao mesmo tempo, subverte o provérbio, resultando em uma técnica eficaz de persuasão. Para melhor compreendê-la, convém explicarmos, primeiramente, porque essa modificação proverbial recebe o nome de entremeio. O nome entremeio, na alteração proverbial por nós denominada détournement proverbial de entremeio, advém da leitura de Dias (1999), que registra a acepção do vocábulo entremeio como "um saber fora do lugar”. O pesquisador atribui o conceito de saber de entremeio para a explicação de certas construções linguísticas como a dada a seguir, atribuída a Tom Jobim:

EI: Morar nos Estados Unidos é uma maravilha, mas é uma merda.

E2:Morar no Brasil é uma merda, mas é uma maravilha.

Aparentemente, há um contra-senso nessa afirmação, as duas proposições chocam-se entre si. Propõe-se a X (ser uma maravilha) e, logo após, contrapõe-se a X a 
característica Y (ser uma merda). As proposições podem ser assim explicadas: Eı - Os Estados Unidos são uma maravilha, mas eu não quero morar lá. E2 - O Brasil é uma merda, mas o povo é uma maravilha. Em (EI), localizamos:

a) uma proposição de identidade = ser uma maravilha;

b) uma consequência não esperada = (mas é uma merda) eu não quero morar lá. Em (E2), localizamos:

a) um contraste entre a proposição de identidade = ser uma merda;

b) um aspecto da totalidade fundadora da proposição = o "povo" é uma maravilha.

É importante que esclareçamos que Orlandi (1996, p. 23) também utiliza o termo “entremeio", porém, com o intuito de posicionar a Análise do Discurso em relação a outras disciplinas: "No caso específico da análise do discurso (AD), que tratamos como uma disciplina que se faz no 'entremeio' [...] uma disciplina de entremeio é uma disciplina não positiva, ou seja, ela não acumula conhecimentos meramente, pois discute seus pressupostos continuamente".

Para Ducrot (1987), construções como essas estão envolvidas em um jogo polifônico, no qual mais de um enunciador atua na constituição do sentido. Dias (1999), acompanhando o pensamento ducrotiano, esclarece que, em ( $\left.E_{I}\right)$, um dos enunciadores discorda das consequências mais prováveis da proposição de identidade; e, em ( $\left.E_{2}\right)$, há uma discordância de apenas um dos elementos constitutivos da identidade. Em ambos os casos, a afirmação introduzida pelo mas não invalida as proposições de identidade. Esses efeitos de oposição atuam, segundo Dias, em dois planos: no plano da organicidade sintática e no plano do enunciável. O saber de entremeio ganha especificidade na relação estabelecida entre os dois planos. $\mathrm{Na}$ frase dita por Tom Jobim, em (EI), o plano do enunciável permite a compreensão de dois níveis de identidade relativa ao Brasil: ser uma merda e ser uma maravilha, que se concretizam em enunciações diferentes e, por isso, deixam de apresentar contradição. O plano da organicidade, por meio do mas (ativado para marcar a orientação de contraste ou oposição entre as duas sentenças), cruza os dois níveis que passam a ser orientados para um mesmo ponto. Esses dois níveis (o plano do enunciável e o plano da organicidade), operando conjuntamente (como saber de entremeio), propiciam o efeito de "fechamento" de sentido à formulação textual. E, se a 
textualidade é construída para direcionar sentidos, é nesse tipo de construções que o saber de entremeio passa a ser pertinente. "Um saber de entremeio, portanto, se sustenta na tese de que o fato linguístico tem uma realidade material, orgânica e ao mesmo tempo uma realidade enunciativa, de ordem do simbólico" (DIAS, I999, p. I47).

Acatamos o termo utilizado pelo autor e o utilizamos em nosso estudo, visto que ele é perfeitamente aplicável ao détournement, pois apresenta o mesmo tipo de estranhamento semântico, em virtude da orientação simultânea de enunciados em contraste ou oposição em sua estrutura, ou seja, os efeitos de sentido manifestados pelo détournement proverbial de entremeio são compreendidos na trama sutil, resultante do cruzamento de significados operantes no plano da organicidade textual, porém, em maior profundidade, no plano do enunciado, que agrega as operações discursivas.

Perfazemos, portanto, que o detournement, em especial os casos de subversão, envolve uma contradição ao texto-fonte (texto original), por meio da negação parcial ou total, pelo apagamento da negação que aquele encerra, e/ou ainda, pelo acréscimo de expressões adversativas. Chamamos esse processo de retextualização, ou seja, da transformação de um texto em outro. Já os textos geradores de detournement podem ser: provérbios, frases feitas, títulos de filmes, publicidades, humor, músicas populares, frases políticas, textos literários, clichês, slogans, passagens bíblicas etc. Tanto podem ocorrer em meios de veiculação de informações, quanto em conversas cotidianas.

Como se pode concluir, os détournements têm sempre valor argumentativo, em grau maior ou menor. Podemos notar, também que é possível argumentar em sentido oposto. Nisso é que difere a captação (que é argumentar reforçando o mesmo sentido) da subversão (que é a argumentação feita em sentido contrário). Contudo, tudo vai deperder, evidentemente, do contexto mais amplo em que o texto que sofreu détournement se encontra inserido, tanto do texto-fonte, quanto do entorno visual (charges, ilustrações, gráficos etc.), ou ainda do contexto situacional imediato ou mediato. E por último, o acréscimo de mais um tipo de détournemet, que é o détournemet de entremeio (DIAS, 1999). Esse tipo de détournemet ocorre quando o "há um saber fora do lugar", ou seja, o autor adere ao provérbio original (captação) e, ao mesmo tempo, destrói a ideia original (subversão).

Em síntese, tratamos acima sobre a intertextualidade em sentido amplo e suas subcategorias, em sentido restrito e suas subcategorias, sobre a polifonia e sobre o 
détournement por captação e por subversão. Este último do tipo lúdico e do tipo militante. A seguir, na seção reservada a metodologia, trataremos da organização do trabalho, do tipo de pesquisa e do corpus. Também trataremos dos métodos usados para análises e da origem do material analisado.

\section{O DÉTOURNEMENT DE SIMILARIDADE EM ANÚNCIOS.}

A operação do détournement de outro slogan ou détournement de similaridade, chamaremos assim pela semelhança (e até mesmo a paridade) entre os slogans de empresas diferentes, mas por fazer parte do conhecimento popular, e dependendo do contexto poderá ser usado por qualquer empresa em anúncios e propagandas diversas. Ao adotar o détournement de similaridade, uma empresa apodera-se de um slogan já utilizado por outra empresa para divulgar seus próprios produtos. No entanto, a empresa adequa esse slogan aos seus interesses comerciais, passando, assim, a anunciar seus produtos ou serviços. É importante que esse slogan não deixe pistas dos produtos anunciados pela empresa que gerou o slogan-fonte, para que, ao anunciar seus produtos, não seja confundida com a outra empresa.

A adequação contextual do slogan à nova marca requer alguns cuidados básicos. Além de ter o cuidado de não deixar resquícios da empresa anterior, o slogan precisa estar em consonância com os produtos ou serviços anunciados, ou ainda estar diretamente relacionada com campanhas ou promoções realizadas pela nova empresa. A empresa que gerou o détournement pode aderir ou não à mensagem veiculada pela empresa anterior, fazendo uma adequação do slogan aos seus propósitos anunciativos. No entanto, tanto ao aderir ou contrariar o slogan original, há uma operação de adequação, tanto no contexto quanto na forma de uso, ou em relação aos novos produtos divulgados.

Um exemplo disso ocorreu pela empresa Havan ao utilizar o slogan bem conhecido da empresa Pontofrio. No final do mês de novembro ocorre em boa parte do mundo, inclusive no Brasil, um evento chamado de "Black Friday". Esse evento teve origem nos Estados Unidos, e tem como propósito o início das compras do período natalino, oferecendo preços muito acessíveis. A empresa brasileira Pontofrio, ao participar desse evento, iniciou as vendas no site da empresa, com os preços especiais de "Black Friday" à meia-noite da sexta-feira. Para anunciar a promoção, bem como o evento "Black Friday", a 
empresa criou o slogan: "Não durma no ponto". Essa expressão foi usada pela empresa para lembrar aos clientes das promoções anunciadas, alertando para que não dormissem sem comprar seus produtos, já que a promoção aconteceria em um horário em que muitas pessoas preferem dormir.

O slogan "Não durma no ponto" faz menção ao nome da empresa "Pontofrio". Como dito acima, devido a promoção ocorrer muito tarde da noite, a intenção da empresa era que os clientes não dormissem, nem em casa nem na loja virtual da empresa, para que pudessem aproveitar os descontos oferecidos pela empresa, e por conseguinte, efetuassem as compras a partir do horário do início da promoção, à meia-noite.

Atentemos para o anúncio da empresa Pontofrio:

Figura I - Não durma no ponto (Pontofrio).

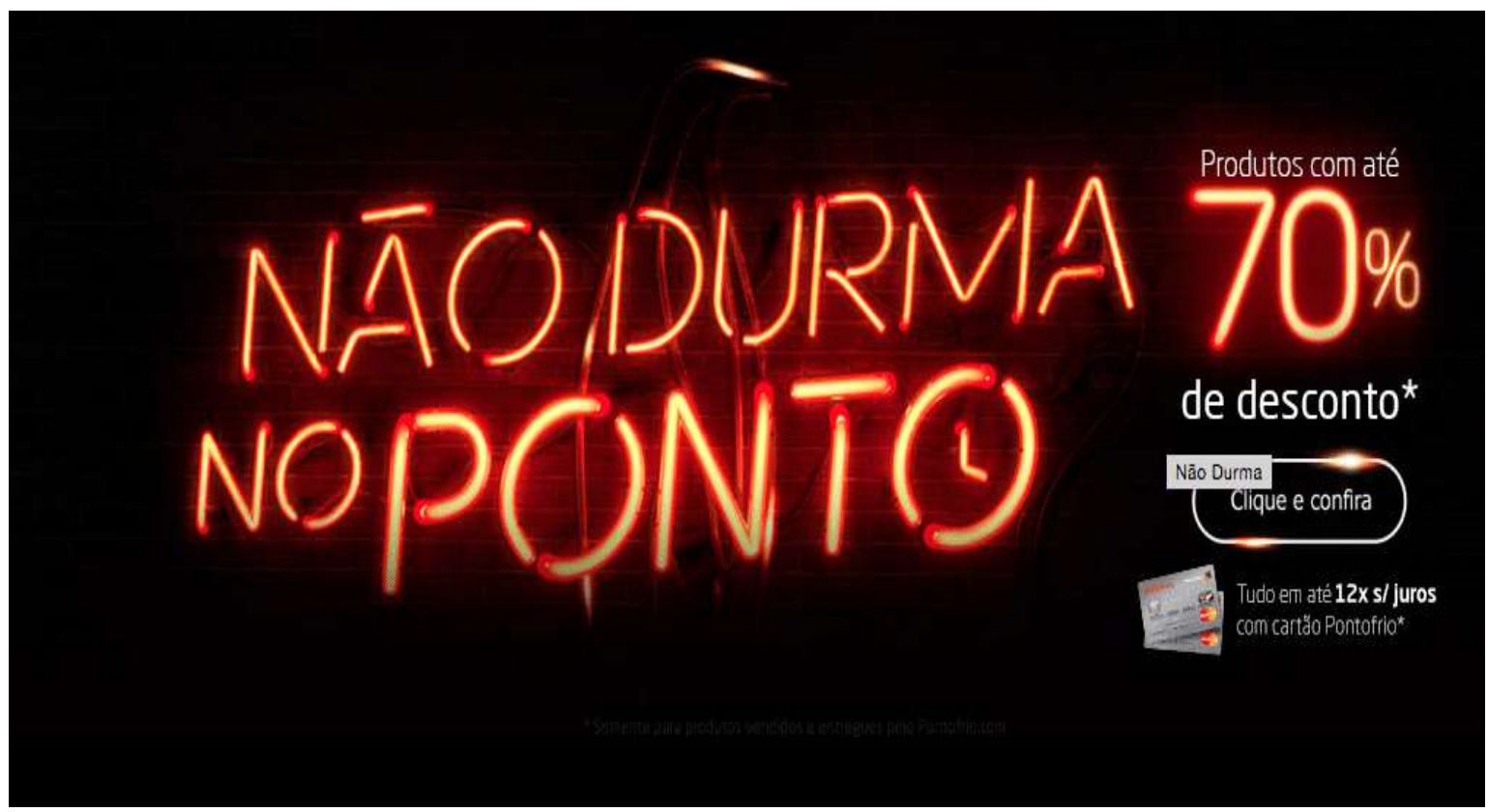

FONTE: Lojas Pontofrio (2017).

O anúncio foi divulgado através de redes sociais, televisão, outdoors, encartes, site da empresa etc. O slogan deu tão certo que a empresa o adotou para sinalizar todos os produtos que estão em oferta, no site da empresa, até a conclusão desse trabalho.

Em contrapartida, a empresa Havan, outra empresa brasileira que atua no setor varejista, adotou o mesmo slogan utilizado pela empresa Pontofrio, para divulgar produtos, em especial travesseiros, comercializados pela empresa. A divulgação ocorreu através da televisão e da plataforma You Tube, com a divulgação de um vídeo com duração de trinta 
(30) segundos. No inicio do vídeo há a utilização de um Meme, gênero textual muito utilizado ultimamente, em que aparece uma mulher convidando a estátua da liberdade para assistirem a um filme. Porém, a estátua começa a dormir. Logo em seguida o locutor anuncia a promoção de travesseiros da Havan com o slogan: "Não durma no ponto, aproveite a promoção de travesseiros deste fim de semana...”. O locutor continua informando os preços dos travesseiros em oferta.

Observemos, a seguir, uma imagem capturada no momento em que o slogan aparece. Vale ressaltar que a imagem foi fotografada da tela da televisão enquanto o vídeo aparecia.

Figura 2 - Não durma no ponto (havan).

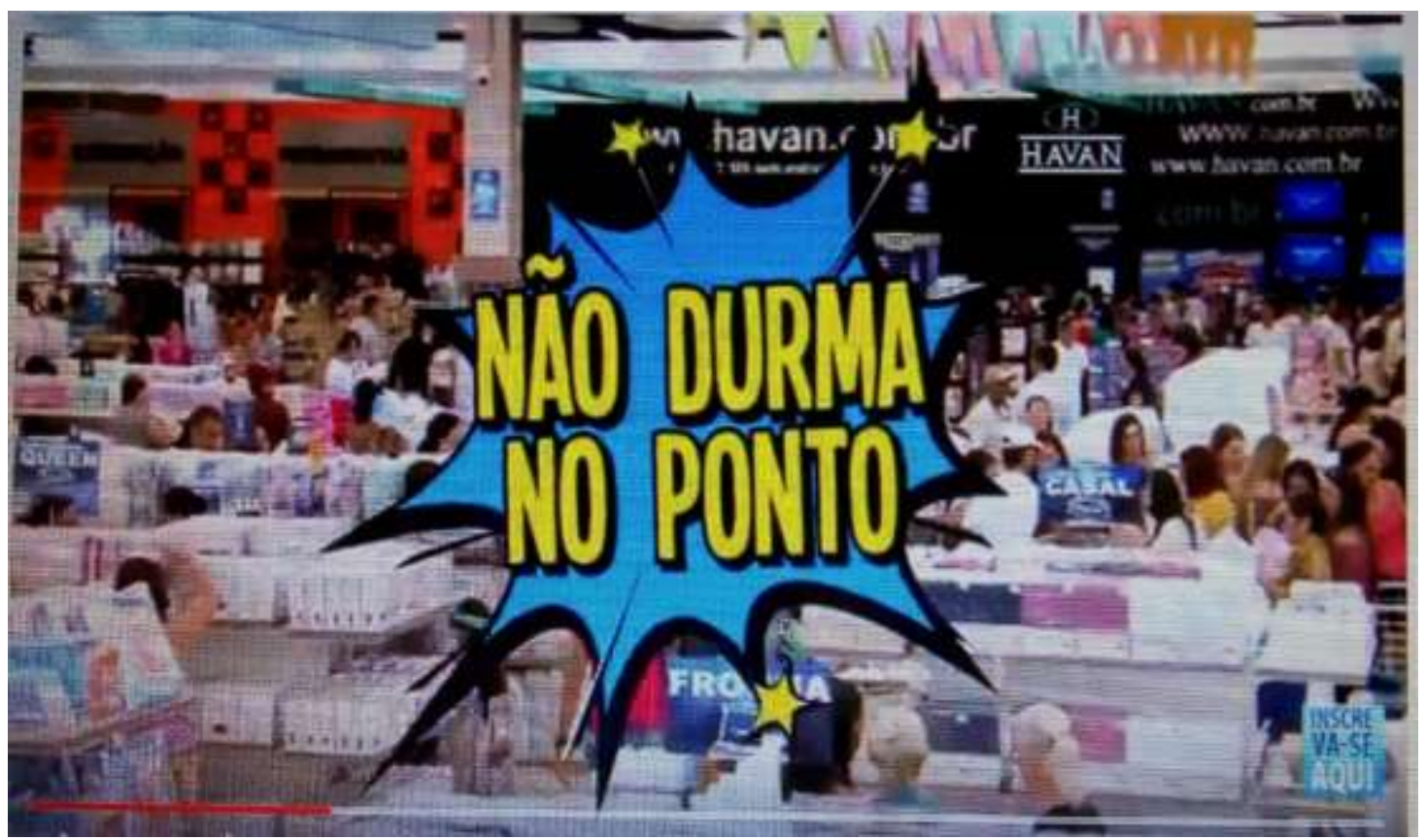

FONTE: Lojas Havan (2019).

Como podemos perceber, a empresa Havan faz uso do mesmo slogan utilizado pela empresa Pontofrio, mas com propósitos diferentes. Enquanto a empresa Pontofrio faz menção ao nome da empresa e ao horário em que os clientes poderiam aproveitar os melhores descontos, a empresa Havan faz menção ao ato de comprar apenas travesseiros. A empresa Pontofrio, ao veicular o anúncio, estava preocupada em alertar os clientes para não dormirem, e assim, aproveitarem os descontos oferecidos. Já a empresa Havan, ao anunciar os travesseiros, se coloca como estando preocupada em oferecer um sono melhor 
aos seus clientes. Para que seus clientes pudessem dormir melhor, eles deveriam aproveitar o final de semana seguinte para comprar os travesseiros em suas lojas.

Nesse caso, ao fazer uso do mesmo slogan, a segunda empresa adequa o uso aos seus produtos anunciados e ao contexto de uso. Podemos perceber que o travesseiro anunciado já faz menção ao sentido de dormir, que juntamente com o slogan, permitem que o texto seja retextualizado. Não ocorrem modificações profundas no texto, em nível de escrita, mas a função dos propósitos comunicativos e os meios envolvidos na atividade comunicativa são ajustados (adequados) para propiciar uma nova situação discursiva, isto é, um novo propósito comunicativo.

Portanto, como uma forma de contribuição aos estudos do détournement, decidimos chamar esse caso de détournement de similaridade, isto é, quando há a transcrição do slogan já usado em uma situação (por uma empresa), e o mesmo slogan passa a ser usado em outra situação sem prejuízo textual, mas passando a ser adequado ao contexto de uso de outra situação (outra empresa usa para anunciar seus produtos). É válido acrescentar que, nesse anúncio, o détournement de similaridade é do tipo militante que opera por subversão, pois mesmo aderindo à reescrita do texto-fonte, o subverte adaptando-o a um novo contexto de uso totalmente distinto.

\section{CONCLUSÃO}

Através dos nossos dados, podemos perceber também que um slogan pode criado para uma determinada finalidade pode ser adequado para outras finalidades. Portanto, o détournement não estabelece limites, o texto pode sofrer alterações (ou não) para se adequar aos mais diversos contextos de uso, com as mais diversas finalidades.

Além do mais, como podemos comprovar através dessa pesquisa e do referencial teórico, a maioria dos casos de intertextualidade implícita podem ser assumidos pelo fenômeno do détournement. O détournement consiste em produzir um enunciado que possui marcas linguísticas de uma enunciação proverbial, podem ser do tipo lúdico ou do tipo militante, este último pode ser por captação ou por subversão.

Os objetivos do uso do détournement é levar o interlocutor a ativar (recuperar) o enunciado original (texto-fonte) para argumentar a partir dele. Essa argumentação pode ser no sentido de ironiza-lo, ridicularizá-lo, contrariá-lo, adaptá-lo a novos contextos de 
uso, ou seja, orientar o interlocutor para um sentido convergente ou divergente do sentido original.

Acreditamos que ao avançarem os estudos sobre o détournement muitas outras operações podem surgir. Pois, mesmo tendo sido postulado há bastante tempo por Grésillon e Maingueneau, em 1984 para sermos mais exato, os estudos envolvendo o détournement não avançaram muito. No Brasil, as pesquisadoras mais conhecidas nos estudos do détournement são Igendore Koch, Ana C. Bentes e Mônica Cavalcante. Sendo que Koch é a que mais usa esse fenômeno em suas pesquisas e livros.

Procurando responder essas questões, nossa pesquisa traz importantes contribuições para as pesquisas do détournement em texto de diversos gêneros, especialmente os textos envolvendo o uso de propagandas e anúncios. Tais contribuições podem servir como base para futuros estudos, tanto para ser usada como contribuição ou para se acrescentar possíveis estudos. Pois, como dissemos, não esgotamos o assunto, mas acreditamos que poderão ser instituídas várias pesquisas nesse viés que complementem ou contestem essa.

Para concluirmos, nesse trabalho estudamos a intertextualidade em sentido amplo e a intertextualidade em sentido restrito. Esta última foi repensada, em termos de uma nova categorização, englobando a compreensão de que o détournement representa a maioria dos casos de intertextualidade implícita.

Investigamos, também, a presença de intertextualidade, em especial do détournement, em propagandas e anúncios e como agem nesses determinados gêneros. Pegamos emprestado de Dias (1999) o détournement de entremeio e juntamos aos postulados por Grésillon \& Maingueneau (1984) e aprofundados por Koch, Bentes e Cavalcante (2008). E ainda instituímos o détournement de similaridade em anuncio e em propagandas.

Acreditamos que ainda possam ser instituídos diversos tipos de détournement, pois não esgotamos o assunto, longe disso, acreditamos que demos apenas um pequeno passo para que esse vasto assunto possa ser mais conhecido, pesquisado e explorado no âmbito acadêmico.

Ademais, diante dos estudos aqui postulados, propomos aos chefes de departamento, professores e demais envolvidos na criação do currículo das disciplinas de Letras que incluam em suas ementas os estudos sobre o détournement baseados em 
Grésillon \& Maingueneau (1984) e Koch, Bentes e Cavalcante (2008). Anexando-os primeiramente aos estudos da intertextualidade, depois aos estudos do texto em geral.

\section{REFERÊNCIAS}

BAKHTIN, M. Marxismo e Filosofia da Linguagem. 2. Ed. Trad. bras. São Paulo: Hucitec, 198I (original russo: 1929).

BANCO BRADESCO. A vida é cheia de previstos. 2017. Portal Bradesco completo. Disponível em: < www.bradescompleto.com.br >. Acesso em: I2 dez. 20I9. I fotografia.

BRANDÂO, H. H. N. Introdução à análise do discurso. 2. ed. Campinas: Editora UNICAMP, 2004 .

DEMO, P. Metodologia do conhecimento científico. São Paulo: Atlas, 2014.

DIAS, L. F. Gramática e ensino do português: abrindo horizontes. In: MOURA, Denilda (Org.). Língua e ensino: dimensões heterogêneas. Maceió: EDUFAL, 2000.

GAIA PROPAGANDA. RB sem medo de ser feliz: Vamos falar sobre bullying. 2013c. Colégio Rio Branco, Gaia Propaganda. Disponível em: $\langle$ http://gaiapropaganda.com/tag/rb-sem-medo-de-ser-feliz/〉. Acesso em: II jan. 2020. I fotografia.

HERNANDEZ, Oswaldo. Comece a década de 70 com os dois pés direitos. 2016. Blog Oswaldo Hernandez.

〈http://memoriasoswaldohernandez.blogspot.com/2012/10/anuncios-de-moda-eacessorios-nos-anos.html>. Acesso em: II jan. 2020. I Fotografia.

JINGLE Lula - Presidente 1989 - Sem medo de ser feliz (com letra). Arquivo Eleitoral. Vídeo, I8 mar. 2016. Plataforma Youtube. Disponível em: 〈https://www.youtube.com/watch?v=1IQwkP6Dlck >. Acesso em: II/oI/20 as I4:54).

KOCH, I. V. Desvendando os segredos do texto. São Paulo: Cortez, 2002.

KOCH, Igendore G. Villaça; BENTES, Anna Christina; CAVALCANTE, Mônica Magalhães. Intertextualidade: diálogos possíveis. São Paulo: Cortez, 2007.

$\mathrm{KOCH}$, Igendore. $\mathrm{O}$ texto e a construção dos sentidos 9. ed. I⿳亠口了 reimpressão. São Paulo: Contexto, 2008.

LOJAS HAVAN. Não durma no ponto. [20-]. Portal Havan. Disponível em: 〈www.havan.com.br〉. Acesso em: in jan. 2020. I fotografia. 
LOJAS PONTOFRIO. Não durma no ponto. [20-]. Portal Pontofrio. Disponível em: $\langle$ www.pontofrio.com.br >. Acesso em: II jan. 2020.

MAINGUENEAU, D. O fato linguístico e a constituição de um saber de entremeio. Leitura - Análise do Discurso, Revista do Programa de Pós-Graduação em Letras e Linguística - LCV-CHLA-UFAL, Maceió, n. 23, 1999, p. 143- I48.

MAGIOLI, T. S. Topoi argumentativos nos provérbios e ditos populares. Revista Philologus, Rio de Janeiro, ano 12, n. 36, dez. 2006. Disponível em: $\langle$ http://filologia.org.br/revista/36/II.pdf $\rangle$. Acesso em: I9 janeiro 2020.

MAINGUENEAU, D. Novas tendências em análise do discurso. Trad. Freda Indursky Campinas: Pontes: Editora da Universidade Estadual de Campinas, $3^{\underline{a}}$ edição, 1997.

MAINGUENEAU, D; GRÉSILLON, A. Polyphonie, proverbe et détournement: ou um proverbe peut en cacher un autre. Langages, n.73. Paris: Larousse, 1984, p. I12-125.

MARQUES, Luciana. Elementos da Análise do Discurso na propaganda do carro Celta. Blog Entrecruzando discursos, 13 dez. 2010. Disponível: 〈http://entrecruzandodiscursos.blogspot.com/2010/12/elementos-da-analise-do-discursona_2059.html?m=1>. Acesso em: 22 set. 2020.

NASCIMENTO, S. S. Ethos, Argumentação e Détournement Proverbial: análise discursiva de um título publicitário da Veja. Parte $\mathrm{I}$ : Um olhar para o linguístico. Revista Línguas \& Letras, v. Io, n. I8, I을.

OLIVEIRA, A. M.. Ditos populares e metáfora conceptual. In: CONGRESSO NACIONAL DE LINGUÍSTICA E FILOLOGIA - CNFL, XIV, n. o4., 2010, Rio de Janeiro. Anais e atas... Rio de Janeiro: Instituto de Letras da UERJ, 2oro. Disponível em:< https://pt.scribd.com/document/404140720/XV-Congresso-Nacional-de-Linguistica-eFilosofia-Tomo-III-pdf $>$. Acesso em: 19 janeiro 2020.

QUEIRÓS, B. C. de. Ler, escrever e fazer contas de cabeça. Belo Horizonte: Miguilim, 1996.

SILVA, J. P. da. Ensaios de filologia. 2. ed. Rio de Janeiro: O Autor, 2005.

SILVEIRA, D. T.; CÓDOVA, F. P. A pesquisa científica. In: GERHARDDT, T. E.; SILVEIRA, D. T. (org.). Métodos de Pesquisa. Porto Alegre: Editora de UFRGS, 2009. p. $3 \mathrm{I}-42$. 